\title{
WAVE ATTENUATION AND SEDIMENT TRANSPORT MONITORING OF LIVING SHORELINES IN THE DELAWARE BAY, U.S.
}

\author{
Katlin Walling, Mott MacDonald, Katlin.Walling@mottmac.com \\ Douglas Gaffney, Mott MacDonald, Douglas.Gaffney@mottmac.com \\ Moses Katkowski, The Nature Conservancy, MKatkowski@tnc.org
}

\section{BACKGROUND}

Living shorelines are considered a more natural approach to shoreline stabilization for low-energy coastlines in contrast to traditional "hard" shoreline armoring methods (i.e. bulkheads). Living shorelines often vary by design and materials, which are optimized for site-specific coastal and environmental conditions, such as wave climate, tidal range, sunlight exposure, etc.; however, the core benefits of all engineered living shorelines are typically the same: reduce shoreline erosion; enhance marine, intertidal, or backshore habitat; and increase resiliency to storm surge and/or sea level rise. While the general benefits of living shorelines are well known, project-specific technical data (i.e. percent of wave energy attenuation, shoreline advancement rates) documenting the effectiveness of living shorelines is more sparse. Moreover, monitoring equipment and analysis techniques required to capture the fine-detailed technical data can prove to be cost and/or labor intensive.

\section{THE STUDY}

The coastal marshes at Gandy's Beach, a town located in southern New Jersey, adjacent to the Delaware Bay (the bay), have significantly deteriorated over the past several decades. Furthermore, the area suffered significant loss of wetlands and shoreline regression as a result of Superstorm Sandy in 2012. Due to the location of Gandy's Beach relative to the mouth of the bay, not only is the town's shoreline exposed to wind-waves generated across the local fetch, it's also exposed to ocean waves propagating into and through the bay (Mott MacDonald, 2016). As the marsh continues to deteriorate, so does the natural habitat and coastal protection provided by the marsh. In an effort to reduce the on-going erosion, stabilize the shoreline, and increase habitat for marine life, The Nature Conservancy (TNC) has installed multiple living shoreline structures paralleling the remaining marsh line along an approximately 2,500 LF section of the shoreline. The living shoreline structures are built of interlocking units forming breakwaters. These breakwater structures are a relatively new type of living shoreline initiative for the Delaware Bay region, thus there was desire to monitor the structures in an attempt to analyze two major components: wave energy attenuation capabilities and localized sediment transport influences.

This study required the methodology developed for monitoring and analysis to be engineered to address several key challenges: the equipment needed to accommodate the 5.5-foot tidal range, which leaves the breakwater structures exposed at low tide; the complexity of small scale sediment transport monitoring and analysis would require dense survey data with high resolution to capture minor elevation changes; and the overall approach would need to be practical and cost effective in order to meet project requirements.

\section{RESULTS}

This paper reports on the monitoring, analysis and performance of the living shoreline breakwater structures with respect to: (1) quantifying the wave energy attenuation capability of the structures to determine their efficacy at reducing wave energy reaching the marsh under varying wave and tidal conditions; and (2) evaluating the influence on localized sediment transport through and around the structures to understand and/or quantify shoreline morphology and accretion landward of the structures. The results are specific for the given coastal and environmental conditions at the Gandy's Beach location on the Delaware Bay, and at the time of monitoring. Multiple monitoring sessions are used in an attempt to identify repeating patterns in the results.

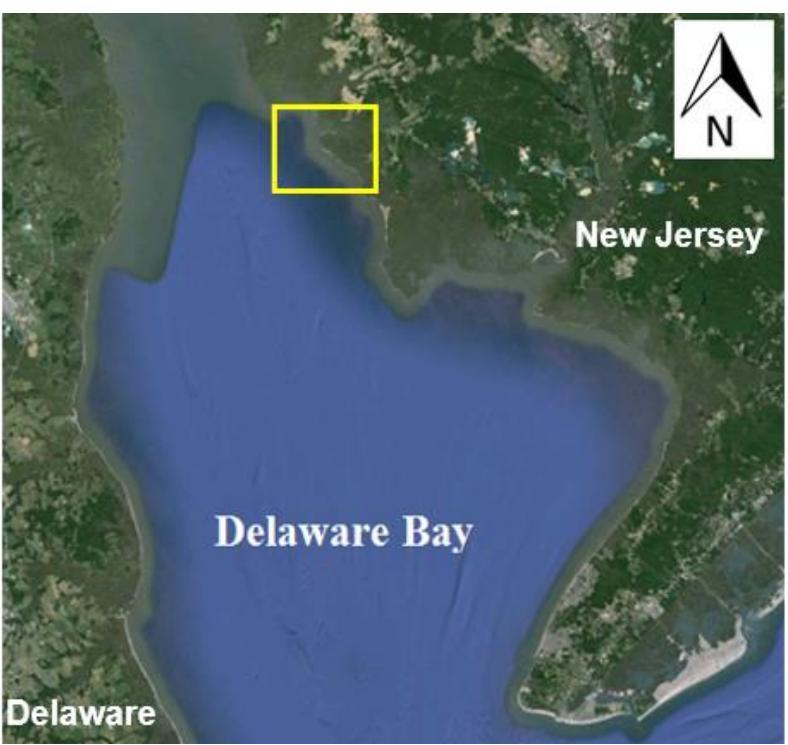

Figure 1 - Location of the Gandy's Beach, NJ living shorelines study area denoted by the yellow box.

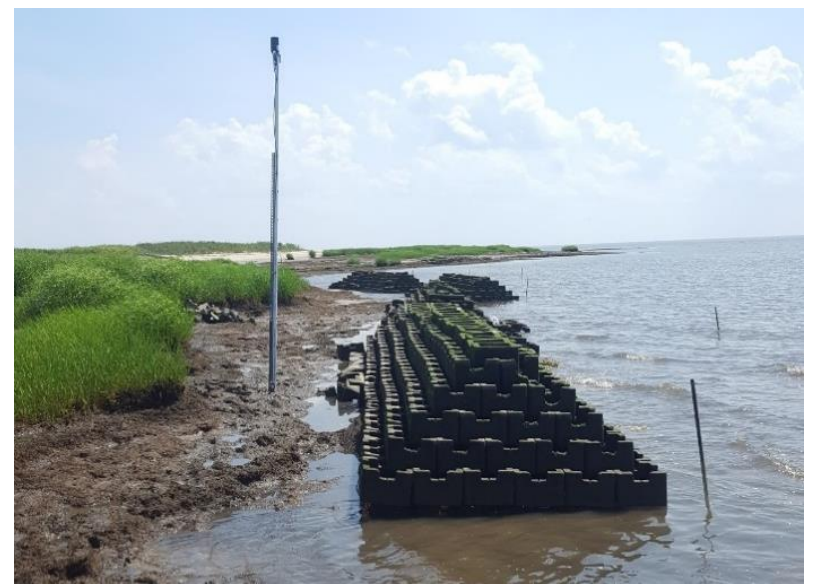

Figure 2 - Living shoreline breakwater structure exposed near low tide at Gandy's Beach, NJ.

\section{REFERENCES}

Mott MacDonald (2016): Gandy's Beach Beachfront Sustainability Project - Technical Report. Feb. 18, 2016 